\title{
Aircraft de Le Corbusier
}

\author{
Marta Sequeira \\ martasequeiracarneiro@gmail.com \\ Professora Auxiliar Convidada Da/UAL \\ Professora Auxiliar Convidada ISCTE-IUL \\ Investigadora Integrada CIAUD-FAUL
}

Para citação: SEQUEIRA, Marta - Aircraft, de Le Corbusier. Estudo Prévio 16. Lisboa: CEACT/UAL - Centro de Estudos de Arquitetura, Cidade e Território da Universidade Autónoma de Lisboa, 2019. ISSN: 2182-4339 [Disponível em: www.estudoprevio.net]. DOI: https://doi.org/10.26619/2182-4339/16.02

Recensão recebida a 17 de dezembro de 2019 e aceite para publicação a 20 de dezembro de 2019.

Creative Commons, licence CC BY-4.0: https://creativecommons.org/licenses/by/4.0/

[...] é como arquitecto e urbanista [...] que me deixo levar nas asas de um avião, que faço uso da vista do pássaro, da vista do ar; é nessa condição que peço ao piloto para sobrevoar as cidades.

Le Corbusier, 1935

Esta recensão crítica tem como objeto de análise Aircraft, livro foi publicado por Le Corbusier em 1935, no mesmo ano em que foi impressa La Ville Radieuse, uma das obras de referência do mesmo autor ${ }^{1}$. Ao contrário de La Ville Radieuse, que assume como título o nome de um projeto de Le Corbusier, Aircraft contém escassas referências à sua obra, ocupando um lugar singular na sua bibliografia. Hoje, 84 anos passados desde a publicação da primeira edição de Aircraft, 60 do surgimento das primeiras fotografias de satélite ${ }^{2}$ e 14 da sua democratização através do Google Earth ${ }^{3}$ - numa altura em que basta tocar um teclado com um dedo para obter uma imagem de satélite de qualquer lugar do mundo -, parece-nos quase impossível começar um projeto sem observar atentamente uma imagem sobranceira do seu sítio. Precisamos, portanto, de fazer o esforço de reconstituir o contexto em que esta obra surgiu para entender as palavras nela inscritas como as de um profeta, que dava como certo que o avião iria mudar radicalmente e para sempre o modo de projetar.

O convite foi feito a Le Corbusier a 16 de janeiro de 1935 por Charles Geoffrey Holme, diretor da revista inglesa The Studio ${ }^{4}$, uma conhecida publicação periódica ilustrada 
PT | L01 | EP16| w2019

sobre artes decorativas: «Faz já algum tempo que tivemos o prazer de receber um contributo seu, mas uma nova série que estamos a preparar poderá ser um bom pretexto para uma nova colaboração. Trata-se de uma série de livros a que demos o nome de The New Vision. Propomos que cada livro desta série se dedique a um sector particular da indústria de design contemporâneo, pensando as novas formas como resultado do trabalho do engenheiro, do arquitecto, do designer e do técnico. Poderíamos dedicar um dos livros aos aviões, outro às locomotivas, e por aí adiante, e pensámos em começar com um livro sobre o avião. Penso que compreenderá o que pretendo quando digo que se trata de uma questão de design que deveria ser vista à luz da imaginação e do sentido de desenvolvimento e progresso deste novo recurso. Gostaríamos de incluir algumas fotografias históricas, que mostrassem os primeiros desenvolvimentos do avião, e outras que mostrassem os mais recentes projectos de aviões, pelo que o livro deveria ser sólido do ponto de vista técnico. No entanto, gostaríamos de avançar um pouco mais ou apresentar o tema de um ponto de vista mais desapegado que o do especialista, e é neste âmbito, acreditamos, que se poderia destacar» ${ }^{5}$.

Charles Geoffrey Holme teria como objetivo a produção de um livro sobre o avião onde, questões técnicas à parte, se mostrasse ao grande público as potencialidades da invenção para a sociedade de então. O livro seria lançado no contexto da coleção «The New Vision», chancela dedicada a introduzir o leitor no mundo das mais modernas invenções tecnológicas, e sob a qual seria mais tarde publicado um livro de Wilfred Watson-Baker sobre o microscópio e um livro de Raymond Loewy sobre a locomotiva. ${ }^{6}$ Ainda que mais tarde tenha vindo a regatear arduamente os seus honorários, Le Corbusier respondeu apenas seis dias depois, prontamente e com entusiasmo: «Recebi a sua amável carta de 16 de Janeiro pedindo-me para preparar o primeiro livro de uma nova coleção que está a organizar. Este primeiro livro seria dedicado ao avião. Por avião, prefiro entender "aviação", isto é, o fenómeno prodigioso que abre horizontes completamente novos e que inclui equipamentos da mais alta relevância. Concordo em aceitar esta colaboração» ${ }^{7}$. Para que dúvidas não houvesse sobre o conteúdo deste livro em particular, e sobre o seu afastamento em relação às questões puramente tecnológicas ou históricas, Le Corbusier terá, portanto, esclarecido primeiramente o editor que não faria um livro sobre o avião, mas sobre 0 fenómeno da aviação de um ponto de vista mais lato, onde pudesse, naturalmente, incluir a sua visão de arquiteto e urbanista.

Le Corbusier manifestou desde sempre o seu fascínio pelo progresso da tecnologia, introduzindo nos seus primeiros livros extensas referências a navios, automóveis e aviões. São disso exemplo os capítulos de Vers une architecture ${ }^{8}$ dedicados às grandes invenções do século XX. Do mesmo modo, este livro celebra a beleza das máquinas do ar e a austeridade funcional dos seus elementos - admiração que, segundo as suas próprias palavras, remonta à época de uma das edições do pós guerra do Salon International de l'aéronautique et de l'espace de Paris-Le Bourget ${ }^{9}$ ou mesmo a 18 de outubro de 1909 quando, da sua mansarda de estudante no Quai St. Michel em Paris, ouviu pela primeira vez o ruído de um avião, nesse caso pilotado pelo aviador Charles, Conde Lambert (russo, com ascendência francesa, mas nascido em Portugal), que, depois de ter partido de Juvisy, rodeou a Torre Eiffel a uma altura de 395 metros do chão ${ }^{10}$. No entanto, Aircraft revela igualmente a condição de urbanista e arquiteto do seu autor, abordando a descoberta da vista de cima: «De repente, graças ao esforço e ao efeito cumulativo das descobertas deste século, fomos presenteados com a VISTA DOS OLHOS DO PÁSSARO». ${ }^{11}$

Entre outros assuntos, as suas observações centravam-se nas possibilidades que a 
PT | L01 | EP16| w2019

«vista de pássaro» traria, no espetáculo de colapso que essa perspetiva revelaria, na necessidade de alteração dos métodos de planeamento urbano que se evidenciariam e na implicação deste novo ponto de vista nas futuras tomadas de decisão. Le Corbusier chegou mesmo a explicar como durante um voo fora possível a revelação de uma ideia de projeto. ${ }^{12}$ Tal como descreveu, "0 próprio avião examina, age rapidamente, vê rapidamente, não se cansa [...] e para quem não tem coragem para ir ver as coisas a partir de cima, estão as fotografias ${ }^{13}$.

Durante o processo de edição, Le Corbusier terá feito pressão para que o livro contivesse mais imagens que retratassem o que era possível observar a partir do avião. Assim escreveu Le Corbusier a The Studio Limited, a 7 de maio de 1935: «[...] estive a analisar o material fotográfico que me enviou: em parte é interessante, mas devo complementá-lo com alguma documentação mais impressionante. Parece-me que falta o que vemos do avião, ou seja: vilas, campo, mar, florestas, etc. ${ }^{14}$. Ainda que a resposta tenha sido a de que não seria possível aprofundar mais sobre o que é visto a partir do avião, "um tema que daria em si para um ou dois livros» ${ }^{15}$, Le Corbusier continuou a contactar diversos interlocutores no sentido de obter fotografias que retratassem essa perspetiva, ${ }^{16}$ tendo acabado por ter à sua disposição uma grande quantidade de fotografias provenientes de diversas coleções oriundas de diversas partes do mundo. Destas, escolheu cento e vinte e três para ilustrar os treze temas tratados ao longo do livro - cuja paginação, feita no atelier de Le Corbusier, ${ }^{17}$ lembra as publicações produto da Bauhaus ou mesmo do construtivismo russo. Destas imagens, vinte e cinco não contêm quaisquer indícios do próprio avião, centrando-se exclusivamente na paisagem que é possível observar a partir dele. Todas são acompanhadas por legendas concisas e evocativas. Nestas, Le Corbusier refere-se ao avião como «0 símbolo de uma nova era» ${ }^{18}$, mas também como um instrumento de observação: «A VISTA DO PÁSSARO. O OLHO AGORA VÊ COM SUBSTÂNCIA O QUE A MENTE APENAS PODERIA CONCEBER SUBJECTIVAMENTE. É UMA NOVA FUNÇÃO ACRESCENTADA AOS NOSSOS SENTIDOS. É UM NOVO PADRÃO DE MEDIDA. É UMA NOVA BASE PARA A SENSIBILIDADE. O HOMEM FARÁ USO DELA PARA CONCEBER NOVAS METAS. AS CIDADES RENASCERÃO DAS SUAS CINZAS». ${ }^{19}$

Publicado originalmente em inglês em 1935, este livro deveria ser, segundo Le Corbusier, publicado em diversas línguas, como o francês, o italiano e o alemão. ${ }^{20}$ No entanto, esta obra prima da imagem e do pensamento arquitetónico apenas foi reeditada em inglês em 198721, em espanhol em $2003^{22}$ e numa versão bilíngue em $2017 .{ }^{23}$ Esta última junta à edição em inglês os textos originais em francês, bem como um artigo de Philipe Duboy, seguido do extenso epistolário trocado por Le Corbusier a propósito da elaboração da primeira edição - que inclui um pedido de reunião a Antoine de Saint-Exupéry com uma hipótese de ponto de encontro irrecusável: no seu novo domicílio, no número 24 da Rua Nungesser et Coli, "[...] de onde se vê o céu $[\ldots] \gg .24$

Le Corbusier - "L'avion accuse..." Aircraft. London, New York: The Studio, 1935.

\footnotetext{
${ }^{1}$ Le Corbusier, La Ville Radieuse. Boulogne: Éditions de l'Architecture d'aujourd'hui, 1935. Le Corbusier desculpa-se do seu atraso no fecho do livro Aircraft precisamente com a impressão de La Ville Radieuse. Ver, sobre este assunto, carta de Le Corbusier a The Studio, datada de 4 de maio de 1935, FLC B3-14-21.
} 
${ }^{2}$ A primeira fotografia de satélite foi feita a 14 de agosto de 1959 pelo U.S Explorer 6.

${ }^{3}$ O programa EarthViewer 3D foi comprado pela Google em 2004 e a 25 de maio de 2005 foi lançado como Google Earth, sendo que em junho de 2005 dispunha de uma versão gratuita.

4 The Studio: An Illustrated Magazine of Fine and Applied Art foi publicada em Londres entre 1893 e 1964, ano em que foi absorvida pela revista Studio International.

5 «It is some time since we have had the pleasure of a contribution from yourself, and a new series that we are contemplating provides an occasion when I think we might very usefully collaborate again. This would be a series of books to which we have tentatively given the general title of "The New Vision". We propose that each book in the series should be devoted to one characteristic section of contemporary design industry, dealing with the new forms that have been created as the result of the efforts of engineer, architect, designer and technician. We should, for example, devote one such book to aeroplanes, another to locomotives and so on, and we thought of beginning with a book on the aeroplane. I think you will see what I mean when I say that this is a technical matter of design which would want handling with imagination and with a sense of the development and future progress of this new feature in human life. We should want to include some historical photographs, showing the early developments of the aeroplane, and many showing the most improved and recent designs of aircraft in every country where they are made, and this would mean that the book would have to be sound in technical particulars. We should want, however, to carry it a stage further or to present the subject, as I have said, from a more detached standpoint than that of the technical expert, and that, we feel, is where you yourself would excel.» carta de Charles Geoffrey Holme, dirigida a Le Corbusier, datada de 16 de Janeiro de 1935, FLC B3-14 (1-2). Le Corbusier refere-se a esta encomenda no próprio livro: «The Studio has informed me of its intention to publish a book on Aviation, the desire of the publishers being to inform the general public, questions of technique apart, as to what stimulus there may be in it for contemporary society, divided at the moment between a desire to retrace its steps and to embark on the conquest of a new civilization.» Le Corbusier, "L'avion accuse..." Aircraft., cit., p. 5.

${ }^{6}$ Wilfred Watson-Baker, World Beneath the Microscope. London: The Studio, 1935; Raymond Loewy, The Locomotive: Its Aesthetics. London: The Studio, 1937.

7 «J'ai bien reçu votre amiable lettre du 16 Janvier me demandant d'établir le premier livre d'une nouvelle collection que vous prévoyez. Ce premier livre serait consacré à l'aéroplane. Par aéroplane, je veux bien comprendre plutôt "aviation", c'est-à-dire tout le phénomène si prodigieux qui ouvre des horizons entièrement neufs et qui comporte déjà des équipements de la plus haute signification. Je suis d'accord d'accepter cette collaboration.» Ver carta de "Le Corbusier, dirigida a Charles Geoffrey Holme, datada de 22 de Janeiro de 1935, FLC B3-14 (3).

8 Ver, sobre este assunto, Le Corbusier, Vers une architecture. Paris: Crès, 1924.

9 Ver, sobre este assunto, Le Corbusier, "L'avion accuse..." Aircraft, cit., p. 5.

${ }^{10}$ Ver, sobre este assunto, idem, ibidem, p. 6.

11 «Suddenly, by the effort of a generation and the cumulative effect of the discoveries of the century, we have been endowed with THE BIRD'S EYE VIEW» idem, ibidem.

12 "Two sketches made during a flight in 1929, just when the conception of a vast programme of organic town-planning came like a revelation.» idem, ibidem.

13 «the airplane itself scrutinizes, acts quickly, sees quickly, does not get tired [...] and there are photographs for those who have not the courage to go and see things from above for themselves» Idem, ibidem, p. 12.

14 «[...] le matériel photographique que vous m'avez expédié, je l'ai parcouru : il est en partie intéressant, mais je dois évidemment le compléter par certaines documentations plus vivantes. Je trouve qu'il manque complètement la matière sur ce que l'on voit d'avion, c'est-à-dire les villes ou les campagnes ou la mer ou les forêts etc." Carta de Le Corbusier, dirigida a The Studio Limited, datada de 7 de Maio de 1935, FLC B3-14 (21).

${ }_{15}$ Ver, sobre este assunto, Carta de The Studio Limited, dirigida a Le Corbusier, datada de 9 de maio de 1935, FLC B3-14 (23).

16 «Pourriez-vous m'envoyer [...] quelques clichés caractéristiques montrant les villes italiennes vues d'avion», carta de Le Corbusier, dirigida a Pollini, datada de 14 de maio de 1935, FLC B314 (53). «Pourrais-je vous demander le grand servisse de demander au ministère de l'Aéronautique des documents assez sensationnels [...] de prises de vues sur le désert ou sur 
les Apennins, ou sur le mer, etc., etc.» carta de Le Corbusier, dirigida a Guido Fiorini, datada de 14 de Maio de 1935, FLC B3-14 (54).

17 Le Corbusier refere: "Le livre sera terminé demain, maquettte complète avec toutes les légendes et toutes mises en pages, et je chercherai à vous l'expédier par avion, si possible», carta de Le Corbusier, dirigida a The Studio Limited, datada de 31 de maio de 1935, FLC B314 (30); «J'ai fait la maquette complète et j'ai mis toutes les annotations nécessaires en cours de route.» carta de Le Corbusier, dirigida a The Studio Limited, datada de 4 de junho de 1935, FLC B3-14 (32). Charles Geoffrey Holme, por sua vez, refere: «The final format of the book necessitates some adjustment of size and arrangement, but we have kept as faithfully as possible to the spirit and general arrangement of your maquette.» carta de Charles Geoffrey Holme, dirigida a Le Corbusier, datada de 21 de junho de 1935, FLC B3-14 (34).

18 «the symbol of a new age» Le Corbusier, "L'avion accuse..." Aircraft, cit., p. 13.

19 «THE BIRD'S EYE VIEW. THE EYE NOW SEES IN SUBSTANCE WHAT THE MIND FORMERLY COULD ONLY SUBJECTIVELY CONCEIVE. IT IS A NEW FUNCTION ADDED TO OUR SENSES. IT IS A NEW STANDARD OF MEASUREMENT. IT IS A NEW BASES OF SENSATION. MAN WILL MAKE USE OF IT TO CONCEIVE NEW AIMS. CITIES WILL ARISE OUT OF THEIR ASHES, ídem ibidem.

${ }^{20}$ «J'ai mis en note également l'éventualité que l'on pourrait envisager de faire une publication en français, une en italien, une en allemand", carta de Le Corbusier, dirigida a The Studio Limited, datada de 4 de junho de 1935, FLC B3-14 (32).

${ }^{21}$ Le Corbusier, "L'avion accuse..." Aircraft. London, New York: The Studio, 1987.

22 Le Corbusier, “L'avion accuse...” Aircraft. Madrid: Abada, 2003.

${ }^{23}$ Le Corbusier, Phylippe Duboy, "L'avion accuse..." Aircraft. Marseille: Parenthèses, 2017.

24 «[...] d'où l'on voit le ciel [...]», Carta de Le Corbusier a Saint-Exupéry, datada de 21 de Março de 1935, FLC B3-14 (50). 